TP Periodica Polytechnica

Social and Management

Sciences

25(1), pp. 25-31, 2017

DOI: $10.3311 /$ PPso.8992

Creative Commons Attribution (i)

RESEARCH ARTICLE

\section{On the Efficiency of Solvency Optimizing Guaranteed Returns in the Insurance Sector}

\author{
Borbála Szüle ${ }^{1 *}$
}

Received 08 January 2016; accepted after revision 19 March 2016

\begin{abstract}
Present low interest rates environment brings about numerous economic effects. Insurance companies are also strongly affected, since traditional insurance products often provide guaranteed returns to policyholders. As guaranteed returns are related to market interest rates, the question about the optimality of currently applied guaranteed returns becomes increasingly compelling in the insurance sector. This paper examines optimality of guaranteed returns from a solvency aspect. With the applied theoretical approach it is possible to identify multiple optima, from which the ,best” is defined as the efficient one. In this framework, some theoretical properties of optimal guaranteed returns are described and existence criteria for the efficient optimum are derived. The paper aims at contributing to the literature also by highlighting a price sensitivity related effect of the choice of guaranteed returns in the insurance sector.
\end{abstract}

\section{Keywords}

solvency, risk analysis, insurance, regulation

\section{Introduction}

Insurance constitutes an important ingredient of financial intermediation, thus it is by no means surprising that interest rates may affect profitability and solvency in the insurance industry. Apart from the conventional effects on investment outcome, market returns also have an insurance-specific channel, through which solvency can be affected: premium calculation in life insurance is frequently based on guaranteed returns that, in turn, are linked to market rates. To sum up, in traditional life insurance premium calculation, similar to financial valuation methods, an essential part of the calculation is the quantification of discounted cash flow values, and the discounting interest rate (sometimes also referred to as technical rate of return) can be considered as a guaranteed return, according to the related equivalence premium principle which is described by for example Banyár (2003:p.185) and (Dickson et al., 2011:p.146). In order to safeguard solvency of insurance companies, the maximum possible guaranteed returns are generally also fixed by regulation (CEIOPS, 2005).

The relationship of market rates and guaranteed returns in insurance have already been incorporated into theoretical microeconomic models by assuming the application of an actuarially fair interest rate (e.g. Yaari, 1965), or for example with the application of market rate related interest in numerical calculations (Borch, 1980). It is worth mentioning that in practice, guaranteed returns in life insurance are usually less than the market rate for risk-free assets of the same maturity (Briys and de Varenne, 1997), so that the guaranteed return can be considered as a conservative estimate of future investment earnings (Holsboer, 2000).

The incorporation of guaranteed returns into traditional life insurance premium calculation can be financially risky for life insurance companies if market interest rates decrease persistently. Previous studies confirmed that the recent low interest rate environment has made it more challenging for life insurance companies to manage their assets and liabilities (e.g. Berend et al., 2013), and that traditional life insurance return guarantees may have substantial market value (e.g. Persson and Aase, 1997). Empirical studies also point out the

\footnotetext{
${ }^{1}$ Insurance Education and Research Group, Faculty of Economics, Corvinus University of Budapest

${ }^{*}$ Corresponding author, e-mail: borbala.szule@uni-corvinus.hu
} 
potential solvency risk in the life insurance industry in the prevailing period of low interest rates (e.g. Kablau and Weiß, 2014; EIOPA 2014). Due to the upcoming introduction of the new Solvency II rules in the European Union in 2016, the optimality of guaranteed returns in insurance business becomes an increasingly compelling question. The paper introduces a theoretical approach to examine this question.

The paper argues that optimality can be defined in several ways, depending on the scope of the analysis. For instance, profitability and solvency aspects could be examined separately, but these are combined to arrive at a solution that is called „efficient” optimum in the paper. Theoretical properties of the efficient optimum are outlined in the general case, and existence criteria are derived under a specific assumption about the price sensitivity of insurance demand. The contribution of the paper to previous literature lies in the construction of the theoretical model and the emphasis put on price sensitivity issues in determining an optimal guaranteed return for insurance companies. Although insurance demand has been quite extensively researched previously (e.g. Andersson-Eriksson, 2015; Economides, 1982; Outreville, 2014), literature has not yet focused on a potential effect of price sensitivity on optimal guaranteed returns, although an effect of this kind is not impossible. A potential reason for a demand effect may be that according to the mathematics of equivalence principle based premium calculation method, the net price of the life insurance cover (the net premium) is lower, if the guaranteed return is higher. Thus, fierce competition in the insurance industry may result in high guaranteed returns. (BIS, 2011) Empirical research results also revealed that price sensitivity of consumer demand, that is not necessarily equivalent to an effect of price competition, may be non-negligible for certain types of life insurance (e. g. Babbel, 1985). In the paper, price sensitivity is modeled by the assumption of a guaranteed return related insurance portfolio size. Results of the paper indicate that an efficient optimum for the guaranteed return may theoretically exist, its practical availability can however be impeded by economic and regulatory constraints.

The paper is organized as follows. Section 2 introduces the theoretical model of the insurance company. Section 3 provides an introduction about the properties of the optimal solutions, and Section 4 presents theoretical results about existence criteria belonging to efficient solutions for optimal guaranteed returns. Section 5 concludes and describes directions for future research.

\section{The model}

The model aims at involving the most important features of insurance companies with an insurance portfolio consisting of traditional insurance products. Although there are certain differences between life and non-life insurance, the applied theoretical abstractions make it possible to capture some common characteristics of insurance products. Nevertheless, it also has to be emphasized that the issue of return guarantee is more prevalent in life insurance. In addition to this, one also has to be aware of a traditional distinction that can be made between those life insurance contracts whereby the insurance company guarantees a specific return to the policyholder, and the unit-linked contracts (without guaranteed return). (BIS, 2011) The distinction between these types of contracts is relevant also from the point of view of solvency: according to the new Solvency II rules capital requirements may be lower for unit-linked insurance products, as in case of many unit-linked products investment risk is borne by policyholders. (ECB, 2007:p.7) In the paper only classical insurance products with guaranteed returns are modeled, thus from a practical point of view, the generally formulated results apply primarily for traditional life insurance (this being that part of the insurance industry, where the optimality issue of guaranteed returns is most prevalent).

According to Insurance Europe (2014:p.23) the majority of assets on the asset side of balance sheets of insurance companies is related to bonds, and the largest component on the other side of the balance sheet is associated with insurance liabilities. This balance sheet structure can be considered as a consequence of the traditional features belonging to insurance activity: traditionally insurance companies take insurance risks, receive premium payments and invest the majority of collected premiums (mainly into bonds). A stylized balance sheet for an insurance company is presented on Fig. 1:

\begin{tabular}{l|l}
\hline & equity \\
$\begin{array}{l}\text { invested } \\
\text { assets }\end{array}$ & $\begin{array}{l}\text { insurance } \\
\text { liabilities }\end{array}$
\end{tabular}

Fig. 1 Stylized balance sheet

The insurance portfolio consists of individual contracts that are assumed to be similar in the model: it is assumed that the probability belonging to the occurrence of the insurance event (p) is the same for each insurance policy. For each individual insurance policy the following random variable can be defined:

$$
\xi j=\left\{\begin{array}{l}
1, \text { if the insurance event occurs } \\
0, \text { otherwise. }
\end{array}\right.
$$

On company level, the sum of these random variables, assuming that the number of insurance policies is equal to $n$, equals the total number of occurred insurance events:

$$
\sum_{j} \xi_{j}
$$

The random variable in (2) is binomially distributed, and its distribution function can be approximated with the normal 
distribution function for a sufficiently large insurance portfolio. It can be assumed in the model that the number of insurance contracts is higher than the number that is required to a good approximation with the normal distribution function.

In practice, an insurance contract can be quite complex, this model however concentrates on its most important features: it is assumed that on the one hand the policyholder pays a single premium (net premium plus certain expenses) and on the other hand policyholders are entitled to receive the sum insured $(B)$ if the insurance event occurs during the term of the insurance. It is assumed that the insurance is issued with a one year term. The guaranteed return (technical rate of return) belonging to the insurance contracts is indicated by $i$ in the model. In Hungary this maximum rate was $2.9 \%$ in July 2015 (61/2013. (XII. 17.) NGM r.) which is lower than previously, for example as of 15 th July 2000, when the maximum rate was $5.5 \%$. In some other European Union countries there have also been developments in guaranteed interest rates applied in life insurance premium calculation, for example (with effect from 1st January 2011) Denmark lowered this rate for new life insurance contracts from $2 \%$ to $1 \%$. (EIOPA, 2011)

Based on these assumptions, and by applying the equivalence principle (as described in (Banyár, 2003:p.185) and (Dickson et al., 2011:p.146)), the net premium payable by the policyholder at the beginning of the insurance term equals:

$$
B \cdot p /(1+i)
$$

At the beginning of the insurance term the sum of collected net premiums equals the value of insurance reserves (that correspond to insurance liabilities). The number of insurance contracts depends on the guaranteed return and is thus indicated by $n(i)$. Demand for insurance products are measured with the number of sold insurance policies in the paper.

It is also assumed that (according to usual microeconomic assumptions) if the insurance premium is lower (as a consequence of a higher guaranteed return), then the demand for the specific insurance type is higher, that can be formulated as

$$
\partial n(i) / \partial i>0
$$

The paper does not aim to explore possible price competition issues within the insurance industry, the presented analysis focuses on a single insurance company for which the size of the insurance portfolio (the number of insurance contracts) depends on the value of guaranteed return.

Beside insurance liabilities, the insurance company is assumed to have own funds (equity) as well, and without loss of generality it can be assumed that equity is defined as in (5) with the application of a ,solvency multiplier" indicated by $s$ :

$$
s \cdot B \cdot p \cdot n(i) /(1+i)
$$

In the model, it is also assumed that at the beginning of the insurance term the collected net premiums and the equity are invested into financial assets that correspond to regulatory requirements for insurance company investment (as indicated by Insurance Europe (2014:p.23) a large part of assets on the asset side of balance sheets of insurance companies is related to bonds). The expected value of the return on these investments can be assumed to be higher than the guaranteed return. In practice, excess return sharing (over the guaranteed return) is often also regulated (the insurance company receives only a part of the excess return). That part of the return on the financial investments, that does not contain the part of policyholders from the excess return (with taking into account return sharing rules as well), is indicated by $r$ in the model. Since the presented analysis concentrates on the choice of guaranteed returns, $r$ is not assumed to be a random variable (however it can be assumed that $r$ is higher than $i$ ). The rate that is applied for discounting is indicated by $k$ in the model.

Profitability and solvency are two key concepts in an insurance related analysis. In the paper, measures for these concepts focus on insurance risk, and take the random nature of insurance events also into account. According to Panjer (2001) the modelling of the loss present value distribution may prove to be useful when constructing for example solvency measures for lines of business of an insurance company. The present value of loss in this model is described by (6):

$$
\begin{aligned}
\eta & =B \cdot \xi /(1+k) \\
& -n(i) \cdot B \cdot p \cdot(1+s) \cdot(1+r) /((1+k) \cdot(1+i))
\end{aligned}
$$

Based on the present value of loss it is possible to define measures for profitability and solvency. In both cases there is a broad range of possible measure, in case of profitability one of the simplest is the expected value of profit present value, which is defined as $E(\mu(i))=-E(\eta(i)$. This amount is affected by the guaranteed return:

$$
n(i) \cdot B \cdot p /(1+k) \cdot((1+s) \cdot(1+r) /(1+i)-1)
$$

As far as solvency is concerned, there are also several measures of solvency risk, either related to the calculation of failure probabilities (e.g. Barnhill and Schumacher, 2011), or associated with an other method, for example with the calculation of regulatory capital ratios (e. g. Pierret, 2015). Literature also mentions the concept of Value-at-Risk (VaR) as having become a standard risk measure used to evaluate exposure to risk in an institution. (Panjer, 2001) VaR can be interpreted as the amount of capital required to ensure that a specific institution (for example insurance company or bank) does not become technically insolvent with an adequately high degree of certainty. (McNeil et al., 2005:pp.43-44; Panjer, 2001) CEA and Mercer Oliver Wyman (2005) show that the majority of surveyed insurance solvency assessment models applied the standard VaR approach, with the Swiss Solvency Test applying Tail VaR, being the only exception among the surveyed models. VaR is also a key risk measure in the new Solvency 
II regulation in the quantification of solvency capital requirements. (Directive 2009/138/EC, Article 101)

Since the present value of loss in (6) is a (linear) function of the sum of insurance events in the model, it is also a random variable with normal distribution. Based on this result and according to (McNeil et al., 2005:p.39) the Value-at-Risk (VaR) belonging to the present value of loss (at alpha confidence level) can be calculated as in (8):

$$
\begin{aligned}
& n(i) \cdot B \cdot p \cdot(1-(1+s) \cdot(1+r) /(1+i)) /(1+k) \\
& +\Phi^{-1}(\alpha) \cdot B \cdot \sqrt{p \cdot(1-p) \cdot n(i)} /(1+k)
\end{aligned}
$$

It should be noted, that other measures for profitability and solvency could also be constructed. In the following it is shown that alternatively defined objectives during the optimization do not necessarily lead to the same solutions.

\section{Optimal solutions}

Based on the model assumptions, the condition for a profit maximizing guaranteed return can be calculated with the maximization of the expression in (7):

$$
\begin{aligned}
& (1+i) \cdot(\partial n(i) / \partial i) / n(i)= \\
& (1+s) \cdot(1+r) /((1+s) \cdot(1+r)-(1+i))
\end{aligned}
$$

In contrast to this result, the solvency risk optimizing guaranteed return (that minimizes VaR) can be calculated from (8):

$$
\begin{aligned}
& B \cdot p /(1+k) \cdot(\partial n(i) / \partial i) / n(i) \cdot(1+s) \cdot(1+r) /(1+i) \\
& -B \cdot p /(1+k) \cdot(\partial n(i) / \partial i) / n(i) \cdot 0.5 \cdot \Phi^{-1}(\alpha) \cdot \sqrt{p \cdot(1-p) / n(i)} \\
& -B \cdot p /(1+k) \cdot(\partial n(i) / \partial i) / n(i)=n(i) \cdot(1+s) \cdot(1+r) /(1+i)^{2}
\end{aligned}
$$

For different solvency multipliers, Fig. 2 illustrates that solvency and profitability optimizing guaranteed returns differ $(B=1, p=0.048, k=0.1, \alpha=0.995, r=0.0105, n(i)=10000$ $\left.\cdot(1+i)^{27}\right)$ :

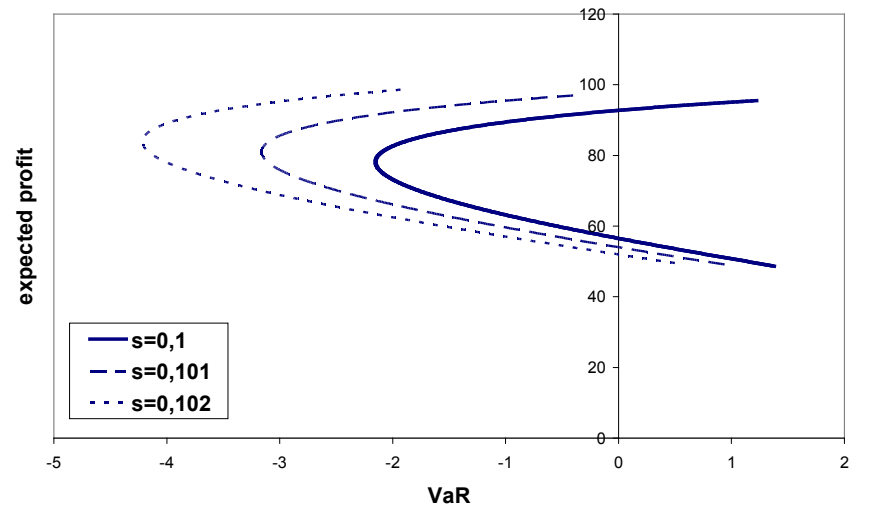

Each data point on Fig. 2 belongs to a different guaranteed return. The solvency optimizing guaranteed return minimizes VaR, while the profitability optimizing return results in the highest expected profit (measured on the vertical axis for the three different solvency multipliers separately). Figure 2 demonstrates that these two optima are not necessarily the same.

Figure 2 also shows that the sign of VaR may be positive or negative. With recalling that the loss variable has a normal distribution, a negative VaR (that belongs to a relatively high confidence level) can be interpreted in such a way that the theoretical mean of loss is also negative, that also indicates that the theoretical mean of the profit is a positive value (and it can be regarded as advantageous for an insurance company from an economic point of view). If the VaR of loss is higher, it can be considered as less advantageous for the insurance company in the model, since in this case solvency risk is higher. In this model framework VaR is only interpreted as a measure of solvency risk. Although (in an adequately designed model framework) VaR values could also be interpreted as solvency capital requirement, it has to be emphasized, that in this model the insurance company is assumed to have an amount of capital that is enough to fulfil regulatory requirements (it means that the value of the ,solvency multiplier", indicated by $s$ in the model, is assumed to be sufficiently high).

As a comparison of (9) and (10) also suggests, alternatively defined objectives may lead to different optimal guaranteed returns (when these optima exists). The question arises, whether the ,best” of these optimal solutions could be selected. One of the possible answers to this question is that there may be cases when it is naturally defined which objective should be of primary importance in an analysis (for example for regulatory purposes solvency optimization could be a reasonable choice). However, even if there is an obvious objective in the analysis, several potential measures for this objective could be developed. For example in case of solvency, VaR minimization is not the only way how the optimal guaranteed return could be computed, for example „company-level” or „contract-level” VaR could also be calculated. This paper concentrates on solvency, and the presented theoretical framework identifies the „best” optimum as the one that minimizes solvency related risks in such a way that profitability aspects are also taken into account. This optimum is called, ,efficient” in the model.

In the model, the efficient optimal guaranteed return is thus identified as the one that combines profitability and solvency aspects of the optimization question, by defining the objective of the analysis in (11):

$$
\begin{aligned}
& \operatorname{VaR}(i) / E(\mu(i))= \\
& -\Phi^{-1}(\alpha) \cdot(1+i) /((1+i)-(1+s) \cdot(1+r)) \cdot \sqrt{(1-p) \cdot n(i) \cdot p}-1
\end{aligned}
$$

Fig. 2 Relationship of solvency and profitability 
The expression in (11) should be minimized, since it reaches its optimum at the smallest ,profit-unit” VaR. Figure 3 illustrates ,efficient" guaranteed return values that minimize the expression in (11) ( $B=1, i=0.01, p=0.048, s=0.1, k=0.1$, $\alpha=0.995, r=0.0105, n(i)=13082)$ :

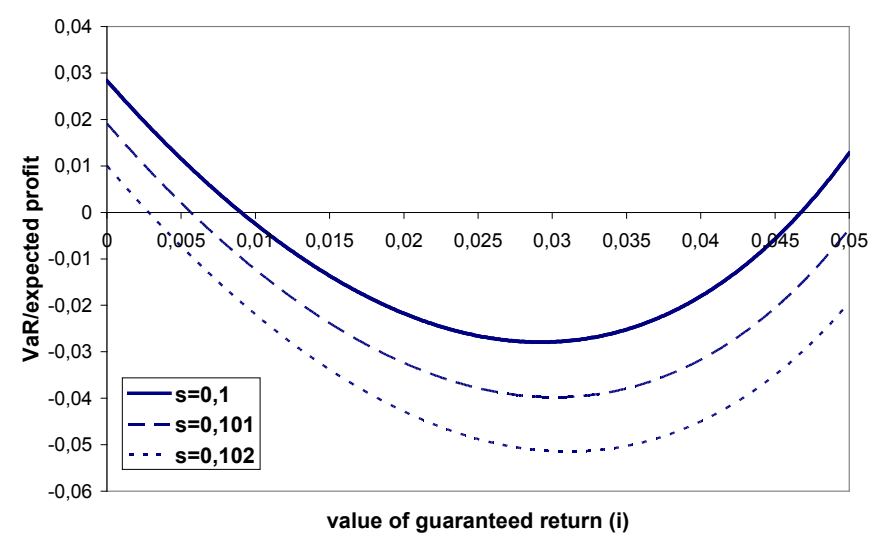

Fig. 3 Efficient guaranteed returns

The optimal solution for an efficient guaranteed return can be calculated based on (12):

$$
\begin{aligned}
& ((1+i) / 2) \cdot(\partial n(i) / \partial i) / n(i)= \\
& (1+s) \cdot(1+r) /((1+s) \cdot(1+r)-(1+i))
\end{aligned}
$$

Mathematically it should also be tested, whether this solution belongs to a minimum value (or a maximum value), but in this analysis it can be assessed as a key result that theoretically an optimal and efficient guaranteed return can exist, if price sensitivity of demand is also taken into account. In the following section, existence criteria for these efficient guaranteed returns are analysed.

\section{Efficient guaranteed returns}

There are several factors that may influence the value of efficient guaranteed returns. It may be possible that a theoretically optimal efficient solution exists, however it could not be practically available, because for example it is higher than the regulatory maximum value. A guaranteed return that could be regarded as practically available is between zero and the regulatory maximum value which is indicated by $i_{\max }$ in the following.

The possible influence of guaranteed return on insurance demand is a key assumption in the model. For the sake of simplicity (and without loss of generality) the guaranteed return dependent insurance demand function (the number of insurance policies) is specified as follows (with assuming a not price sensitive part of the demand, indicated by $c>0$, and also assuming $g>0$ ):

$$
n(i)=c \cdot(1+i)^{g}
$$

This assumption about the size of the insurance portfolio can be interpreted in such a way that insurance demand is not only explained by the guaranteed return, but if the guaranteed return is higher, a larger demand for insurance may be observed. It also means that without assuming price sensitivity of life insurance demand, the number of insurance contracts is a constant value (that does not depend on the value of guaranteed return).

If (13) holds, then the efficient guaranteed return is described by (14):

$$
i^{*}=(1-(2 / g)) \cdot(1+s) \cdot(1+r)-1
$$

By assuming (13), the effects of the main factors influencing the optimum are easier observable. The strength of price sensitivity (indicated by $g$ ) can be regarded as an exogenous factor, similar to the investment return (indicated by $r$ ), since it can be assumed that the insurance company chooses the best available investment portfolio. According to the results (as it could be expected) a low interest rate environment may result in a lower investment return, thus also reducing the optimal efficient guaranteed return.

The solvency multiplier (that is related to regulation, and indicated by $s$ ) is paid more attention in the following, since from a solvency point of view the share of equity within the balance sheet is a central issue. If the efficient solvency multiplier exists, the upper limit for the solvency multiplier is related to the requirement that $i^{*} \leq i_{\max }$ :

$$
s \leq g \cdot\left(1+i_{\max }\right) /((g-2) \cdot(1+r))-1
$$

As far as the lower limit of the solvency multiplier is concerned, there is an obvious rule that at least the regulatory minimum capital should be held (which is indicated by $s_{\max }$ in the model):

$$
S \geq S_{\max }
$$

In addition to this constraint, the requirement $i^{*} \geq 0$ should also be met, which results in an other lower limit for the solvency multiplier:

$$
s \geq g /((g-2) \cdot(1+r))-1
$$

The requirements for an ,available” efficient guaranteed return, which are described by (15), (16) and (17), are illustrated by Fig. 4 ( $B=1, i=0.01, p=0.048, k=0.1, \alpha=0.995$, $r=0.0105, c=10000)$.

Figure 4 shows those pairs of solvency multipliers and price sensitivity indicators (denoted by $g$ in the model) for which the calculated efficient solution could be considered as practically available. However, it should be noted that for a number of reasons it could be problematic to develop practical business decisions based on these mathematical results. The model structure is simplified, and although this makes it possible to 
present results in a more straightforward way, some complex practical interactions between parameters are not captured in the model. Together with these limitations, one of the main results of the paper is that theoretically, in certain cases, a solvency risk optimizing efficient guaranteed return can exist.)

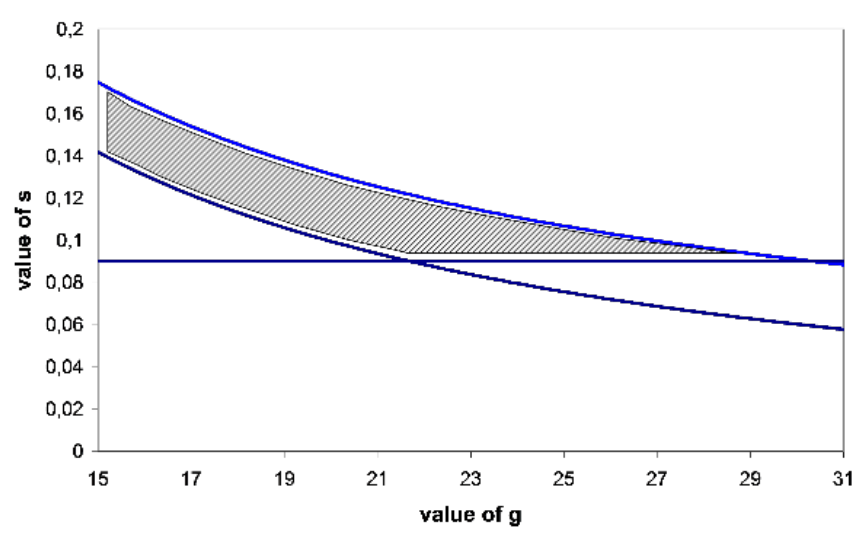

Fig. 4 Set of available efficient guaranteed returns

\section{Conclusion}

The current low interest rate environment has far-reaching economic effects. In the insurance industry (mainly in life insurance) market-linked return guarantees traditionally play a central role in premium calculation, thus influencing many business areas and insurance solvency as well. In light of recent market developments, the question about optimality of guaranteed returns naturally arises. This paper aims to contribute to the literature with the introduction of a theoretical model framework, in which this question can be analysed by also taking into account a previously partly neglected insurance demand effect.

Solvency is also in the focus of this paper, since the new Solvency II regulation is to be implemented in the near future. Although for different objectives several optimal solutions could be calculated, the efficient optimal solution is defined in the paper as the one that optimizes solvency related risk for one „unit” of expected profit, thus also combining solvency and profitability aspects in the analysis.

The key result of the paper is that an efficient optimum for the guaranteed return can exist, although there are some economic and legal constraints that may impede its availability. Despite the relative simplicity of the model, theoretical results point out the complexity of the effects of guaranteed returns on solvency. With a refinement of model assumptions it could be possible to achieve more practice oriented results. Directions for future research include a stochastic modelling of returns on financial investments and the development of model assumptions about surrender behaviour of policyholders.

\section{References}

Andersson, L.-F., Eriksson, L. (2015). The compulsory public pension and the demand for life insurance: the case of Sweden, 1884-1914. The Economic History Review. 68(1), pp. 244-263. https://doi.org/10.1111/1468-0289.12054

Banyár, J. (2003) Életbiztosítás. (Life insurance). Aula Kiadó, Budapest. (in Hungarian)

Babbel, D. F. (1985) The price elasticity of demand for whole life insurance. The Journal of Finance. 40(1), pp. 225-239. https://doi.org/10.1111/j.1540-6261.1985.tb04946.x

Barnhill, T. Jr., Schumacher, L. (2011). Modeling correlated systemic liquidity and solvency risks in a financial environment with incomplete information. IMF Working Paper WP/11/263. [Online]. Available from: http://www.imf.org/pubs/cat/wp1_sp.aspx?s_ year $=2011 \&$ e_year=2011\&brtype $=$ default [Accessed: 8th July 2015]

Berends, K., McMenamin, R., Plestis, T., Rosen, R. J. (2013). The sensitivity of life insurance firms to interest rate changes. Federal Reserve Bank of Chicago, Economic Perspectives, 2Q/2013. [Online]. Available from: http://www.chicagofed.org/publications/economic-perspectives/index [Accessed: 8th July 2015]

BIS (2011). Fixed income strategies of insurance companies and pension funds. CGFS Papers No. 44. Committee on the Global Financial System, Bank for International Settlements. [Online]. Available from: http://www.bis. org/publ/cgfs44.htm [Accessed: 16th July 2015]

Borch, K. (1980). Life insurance and consumption. Economics Letters. 6, pp. 103-106.

Briys, E., de Varenne, F. (1995). On the risk of life insurance liabilities: debunking some common pitfalls. Wharton Financial Institutions Center, 96-29, The Wharton School, University of Pennsylvania. [Online]. Available from: http://fic.wharton.upenn.edu/fic/papers/96/9629.pdf [Accessed: 14th July 2015]

CEA, Mercer Oliver Wyman (2005). Solvency assessment models compared. Comité Européen des Assurances (CEA) and Mercer Oliver Wyman. [Online]. Available from: http://www.insuranceeurope.eu/publications/ publications-web [Accessed: 14th July 2015]

CEIOPS (2005). Report on financial conditions and financial stability in the (re)insurance and occupational pension fund sectors 2004-2005, Risk outlook. CEIOPS-FS-16/05/S, December 2005. [Online]. Available from: https://eiopa.europa.eu/Publications/Reports/FS1605.pdf [Accessed: 8th July 2015]

Dickson, D. C. M., Hardy, M. R., Waters, H. R. (2011). Actuarial mathematics for life contingent risks. Cambridge University Press.

Economides, N. (1982). The demand for life insurance: an application of the economics of uncertainty: a comment. The Journal of Finance. 37(5), pp. 1305-1309. https://doi.org/10.1111/j.1540-6261.1982.tb03621.x

EIOPA (2011). Financial stability report 2011, Second half-year report. EIOPA-FSC-11/057, 19 December 2011. [Online]. Available from: https:// eiopa.europa.eu/Pages/Financial-stability-and-crisis-prevention/Financial-Stability-Reports.aspx [Accessed: 8th July 2015]

EIOPA (2014). Financial stability report. EIOPA-FS-14/105, 15 December 2014, European Insurance and Occupational Pensions Authority. [Online]. Available from: https://eiopa.europa.eu/Pages/Financial-stabilityand-crisis-prevention/Financial-stability-Report_Dec_2014.aspx [Accessed: 14th July 2015]

Holsboer, J. H. (2000). The impact of low interest rates on insurers. The Geneva Papers on Risk and Insurance. 25(1), pp. 38-58. 
Insurance Europe (2014). Why insurers differ from banks. Insurance Europe aisbl, Brussels, October 2014. [Online]. Available from: http://www. insuranceeurope.eu/uploads/Modules/Publications/why_insurers_differ_from_banks. pdf [Accessed: 26th April 2015]

Kablau, A., Weiß (2014). How is the low-interest-rate environment affecting the solvency of German life insurers? Deutsche Bundesbank Discussion Paper No. 27/2014. [Online]. Available from: http://www.bundesbank. de/ [Accessed: 8th July 2015]

McNeil, A.J., Frey, R., Embrechts, P. (2005). Quantitative Risk Management: Concepts, Techniques and Tools. Princeton University Press. 2005.

Outreville, J. F. (2014). Risk aversion, risk behavior, and demand for insurance: a survey. Journal of Insurance Issues. 37 (2), pp. 158-186.

Panjer, H. H. (2001). Measurement of risk, solvency requirements and allocation of capital within financial conglomerates. University of Waterloo, Institute for Insurance and Pension Research (IIPR) Report. [Online]. Available from: https://uwaterloo.ca/waterloo-research-institute-in-insurance-securities-and-quantitative-finance/research-reports/2001-institute-insurance-and-pension-research-reports [Accessed: 14th July 2015]
Persson, S., Aase, K. K. (1997). Valuation of the minimum guaranteed return embedded in life insurance products. The Journal of Risk and Insurance. 64(4), pp. 599-617. https://doi.org/10.2307/253888

Pierret, D. (2015) Systemic risk and the solvency-liquidity nexus of banks. International Journal of Central Banking. 11(3), pp. 193-227.

Yaari, M. E. (1965). Uncertain lifetime, life insurance and the theory of the consumer. Review of Economic Studies. 32, pp. 137-150.

Directive 2009/138/EC of the European Parliament and of the Council of 25 November 2009 on the taking-up and pursuit of the business of Insurance and Reinsurance (Solvency II). [Online]. Available from: http://eur-lex. europa.eu [Accessed: 18th January 2015]

61/2013. (XII. 17.) NGM rendelet a technikai kamatlábak legnagyobb mértékéről. (NGM regulation about the maximum technical interest rates). (in Hungarian) 